\title{
Formocresol and ferric sulfate have similar success rates in primary molar pulpotomy
}

\author{
In carious primary molars does a pulpotomy performed with ferric sulphate, \\ compared with formocresol, result in greater clinical/radiographic success?
}

\begin{abstract}
Loh A, O'Hoy P, Tran X, Charles R, Hughes A, Kubo K, Messer LB. Evidence-based assessment: evaluation of the formocresol versus ferric sulfate primary molar pulpotomy. Pediatr Dent 2004; 26:401-409.
\end{abstract}

Data sources Medline Ovid Library, the Cochrane Library, PubMed, Embase, Science Citation Index (SCI) and System for Information on Grey Literature in Europe (SIGLE).

Study selection Reviews, full reports, or research abstracts of prospective, retrospective, comparative, and/or radiographic studies were included, while case reports and letters were excluded.

Data extraction and synthesis $A$ total of 13 studies (three randomized clinical trials and 10 clinical trials) contributed to the meta-analysis, one randomized clinical trial and one clinical trial were analyzed by the direct technique, and all 13 trials were analyzed by the indirect technique. Data from trials were divided into clinical and radiographic data, and separate statistical analyses were conducted using the direct technique. Odds ratios (ORs) were used to compare the relative success of ferric sulphate and formocresol. Data homogeneity was tested using the $\chi^{2}$-test of consistency on the ORs for each trial.

Results Clinical data indicated that ferric sulphate was significantly more successful than formocresol $(\mathrm{OR}=1.95 ; \mathrm{Cl}=1.01-3.80)$. Radiographic data indicated no difference between medicaments $(\mathrm{OR}=0.90$; $\mathrm{Cl}=0.58-1.39)$. Medicaments did not differ with $t$-tests of clinical $(P>0.10)$ and radiographic $(P>0.50)$ data.

Conclusions In human carious primary molars with reversible coronal pulpitis, pulpotomies performed with either formocresol or ferric sulphate are likely to have similar clinical/radiographic success.

\section{Commentary}

For a number of years there has been a debate about the appropriateness of formocresol as a vital pulpotomy material, there being concerns regarding the safety of its principal component, formaldehyde. Therefore, there is great interest in the effectiveness of alternative materials. This systematic review and meta-analysis provides useful information on the effectiveness of one alternative material, ferric sulphate, when compared to formocresol.

The paper starts with a lengthy, well-written synopsis on evidence-based dentistry; however, this is somewhat superfluous in this paper. The paper refers in the last paragraph to the existing Cochrane Systematic Review, ${ }^{1}$ calling it brief, but noting that these two reviews both conclude that "there is no reliable evidence supporting the superiority of one particular treatment method for pulpally involved primary molars." It would have been valuable if this review had spent more time discussing the Cochrane Review explaining the differences in approach and methodology of the two reviews. Other than these two criticisms, this is a well conducted and reported review.

The trials were analyzed in two ways: those where formocresol and ferric sulphate were compared head to head (two trials), and trials reporting either technique (13 trials). There were more data available for formocresol than ferric sulphate. This review concluded that both pulpotomy techniques were likely to be successful and neither was more effective than the other, and emphasizes that vital pulpotomies work. Given the doubts about the safety of formocresol it would also appear that it is more appropriate to use ferric sulphate. However, anecdotally many clinicians feel that formocresol is more successful because it is not as technique sensitive as the alternatives. There is no evidence to support this view.

Many questions remain: what is the most effective pulpotomy technique, should pulpectomy be used instead, or should a more biological approach of indirect pulp capping be advocated? $?^{2,3}$ This excellent review provides a significant step forward both in terms of methodology and information.

\section{Practice point}

- Ferric sulphate is as effective as formocresol for vital pulpotomies in primary teeth.

\section{Chris Deery \\ Paediatric Department, University of Edinburgh, Edinburgh \\ Dental Institute, Edinburgh, UK \\ 1. Nadin G, Goel BR, Yeung CA, Glenny AM. Pulp treatment for extensive decay in primary teeth. Cochrane Database of Systematic Reviews 2003; 1:CD003220. \\ 2. Faoooq NS, Coll JA, Kuwabara A, Shelton P. Success rates of formocresol pulpotomy and indirect pulp therapy in the treatment of deep dentinal caries in primary teeth. Pediatric Dentistry 2000; 22:278-286. \\ 3. Cass MJ, Kenny DJ, Johnston DH, Judd PL. Long-term outcomes of primary molar ferric sulphate pulpotomy and root canal therapy. Pediatric Dentistry 2004; 26: 44-48.}

Evidence-Based Dentistry (2005) 6, 70.

doi: $10.1038 /$ sj.ebd. 6400348 